\title{
EP637
}

\section{in preoperative treatment of rare NET}

L Papierska ${ }^{1}$, J Ćwikła ${ }^{2}$, M Rabijewski ${ }^{3}$, K Nowak ${ }^{1}$, W Zgliczyński ${ }^{1}$

${ }^{1}$ The Medical Centre of Postgraduate Education, Department of Endocrinology, Warsaw, Poland.

2 University of Warmia and Mazury, The Faculty of Medical Sciences, Department of Radiology, Olsztyn, Poland Medical University of Warsaw, Department of Internal Diseases, Diabetology and Endocrinology, Warsaw, Poland

\section{Introduction}

- Analogues of somatostatin are widely used in management of neuroendocrine tumors. The "classic" indications for this treatment are: acromegaly and NETs of midgut to diminish symptoms caused by hormonal overproduction and slow down the tumors' growth.

However, we consider the use of this medication also in the other cases in which we confirm the presence of somatostatin receptors in tumor by somatostatin receptor scintigraphy.

-We would like to present three cases of symptomatic, resistant to "classic" pharmacological therapy, neuroendocrine tumors, in which only preoperative treatment with long-acting Octreotide enabled successful surgery.

\section{Case 1}

40-years-old man with profound hypoposphataemia caused by GF-23 secreting tumor

in the right maxillary sinus (glomangiopericytoma).
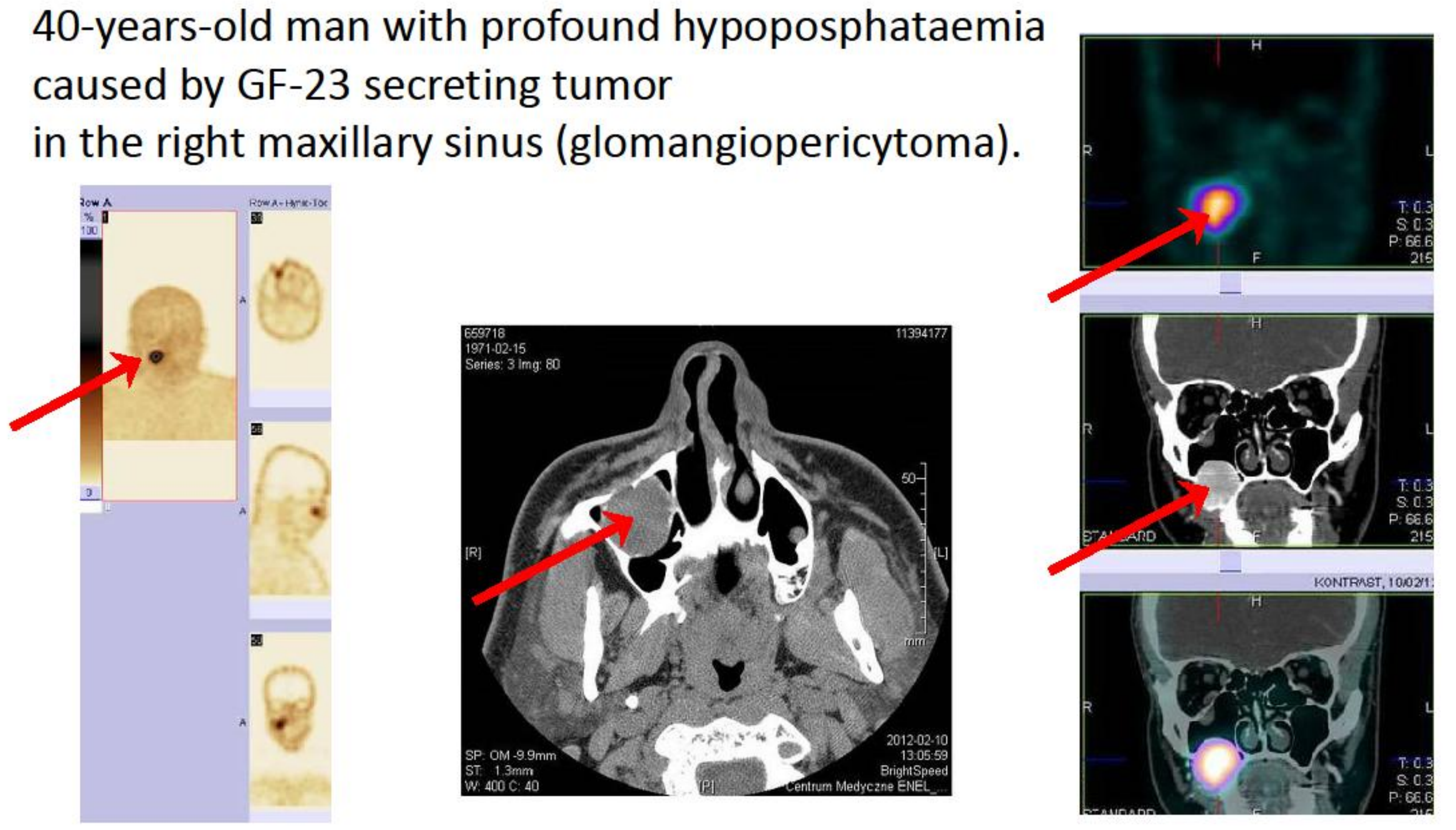

The treatment with phosphorus and active vitamin D metabolites was ineffective. The improvement of phosphorus concentration was necessary for safety of anesthesia and proper function of respiratory muscles after the extubation, so waiting for surgery, the patient was treated initially with Octreotide, then with long acting Octreotide. Phosphorus level increased to proper values.

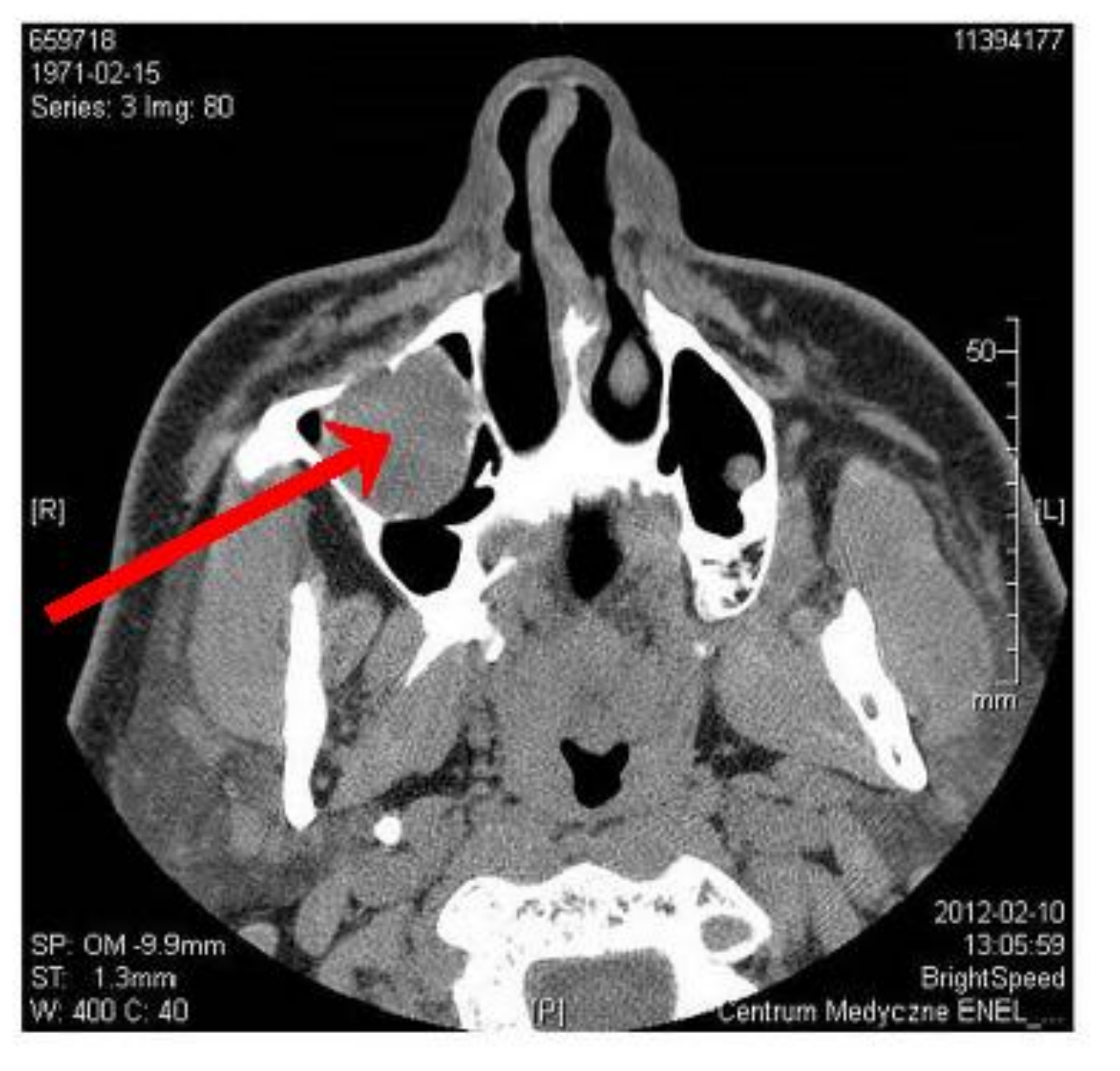

\begin{tabular}{|c|c|}
\hline Before injection & $2^{\text {nd }}$ day after the injection \\
\hline $\begin{array}{c}\text { Phosphorus } 0,41-0,50 \mathrm{mmol} / \mathrm{I} \\
\text { [ref val } 0,75-1,4]\end{array}$ & $\begin{array}{c}\text { Phosphorus } 0,68-0,76 \mathrm{mmol} / \mathrm{I} \\
\text { [ref val } 0,75-1,4]\end{array}$ \\
\hline $\begin{array}{c}\text { Intense pain of the pelvis } \\
\text { Waddling gait }\end{array}$ & $\begin{array}{c}\text { Pain decreased } \\
\text { Normal walking }\end{array}$ \\
\hline
\end{tabular}

Case 2

44-years-old woman with paroxysmal tachycardia and hypertension up to 200/140 caused by catecholamine secreting tumor localized in mediastinum (paraganglioma).

The preoperative treatment with alpha, beta and calcium channel blockers and also $\mathrm{ACl}$ and diuretics was ineffective.

The second day after the Octreotide injection the blood pressure fell down and directly before surgery only the alpha and beta blockers were used.
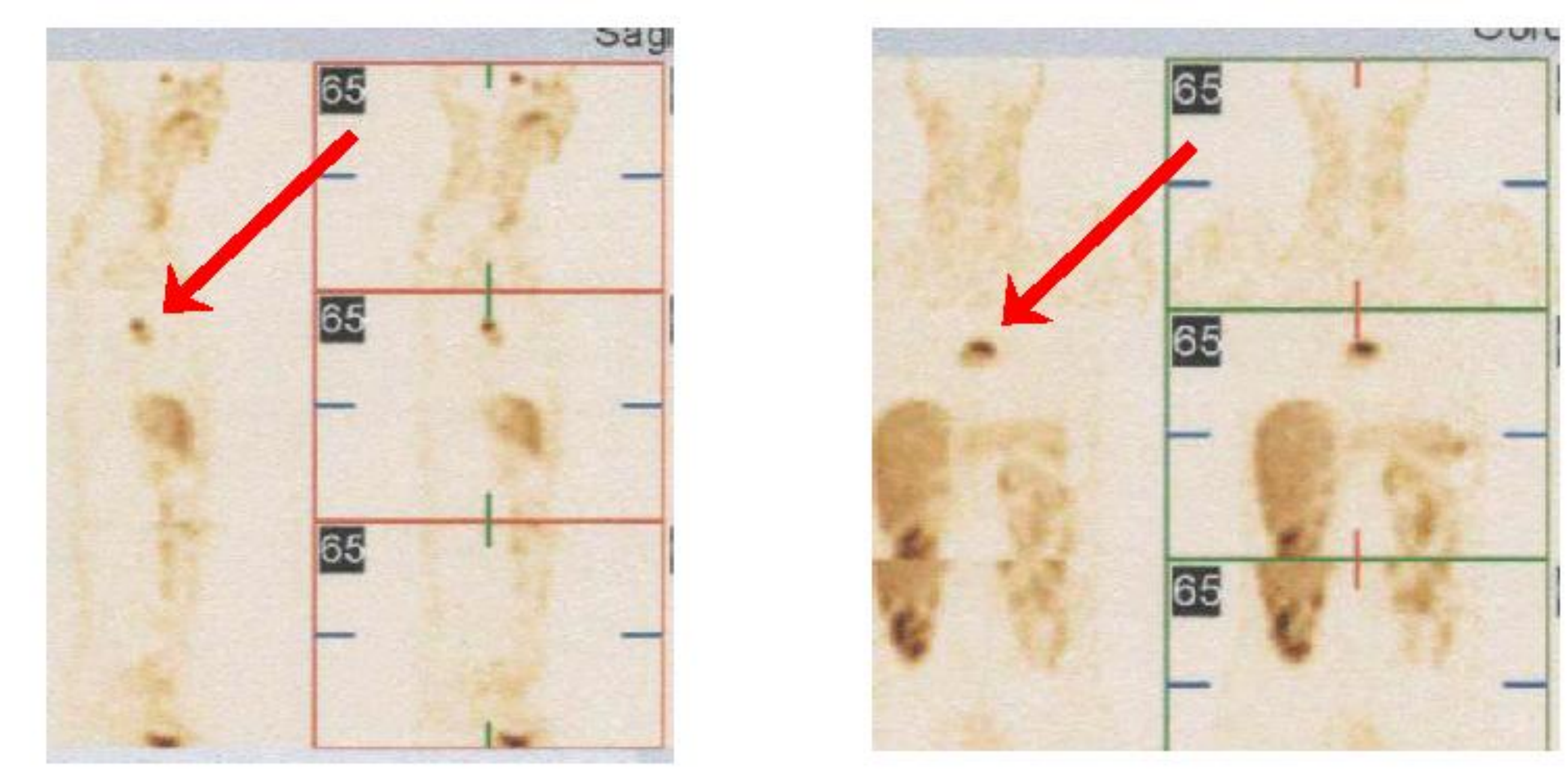

\section{Case 3}

50-years-old woman with paroxysmal sweating and hypertension up to $240 / 140$ caused by pheochromocytoma of the left adrenal gland.

The preoperative treatment with alpha, beta and calcium channel blockers and also $\mathrm{ACl}$ and diuretics was ineffective.

She was twice disqualified from the operation due to blood pressure $>200 / 120$.

After the Octreotide injection the blood pressure fell down $(<140 / 90)$, however, the reduction of the medications before surgery was impossible.
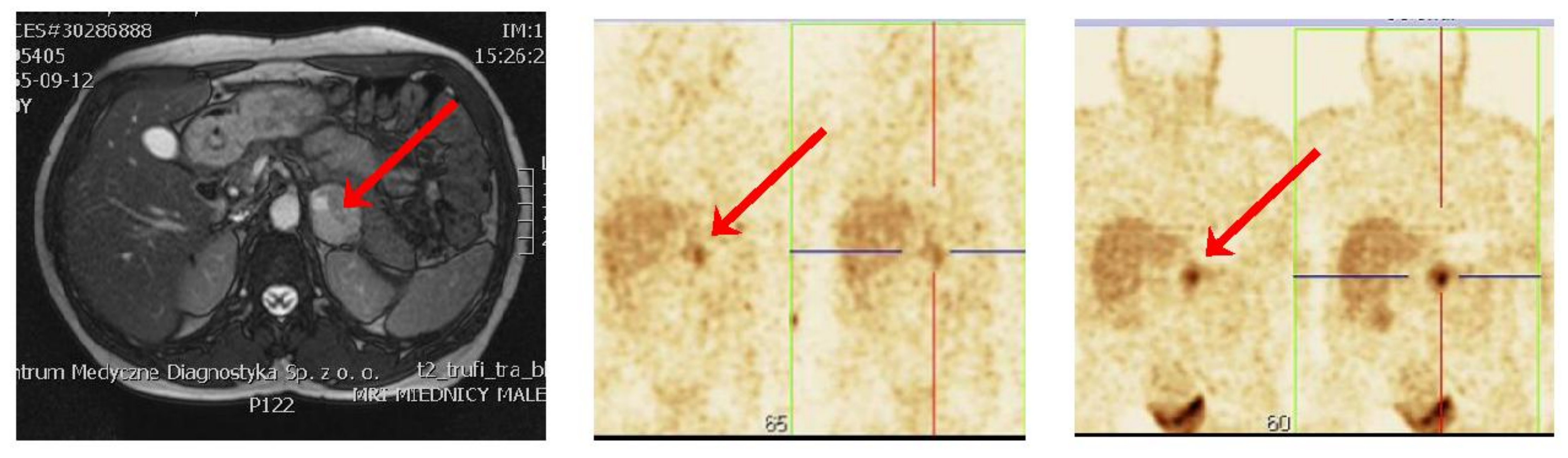

\section{Conclusions}

These cases exemplify possibility of unconventional use of somatostatin or its long acting somatostatin analogues in preoperative treatment of rare neuroendocrine tumors. 